\title{
Posicionamento social e a hipótese da distribuição de renda desconhecida. Brasil: quão pobres, quão ricos e quão desiguais nos percebemos?
}

\author{
RUDI ROCHA \\ ANDRÉ URANI*
}

Social scale and the hypothesis of the not recognized income distribution. Based on the ISSP (1999) survey the aim of the present paper is to provide an empirical description about the perceptions Brazilians have towards their own social positioing in the social scale and towards the country's income distribution. Throughout this description, the paper gives support for the hypothesis that Brazilians do not recognize the form of the country's income distribution and its high degree of inequality. Also, we present a brief discussion on the causes and consequences of this knowledge gap.

Key-words: income distribution, social scale, perception.

JEL Classification: D31, D63, D83, 131.

INTRODUÇÃO

O Brasil é estatisticamente reconhecido como um, senão o país de maior desigualdade de renda no mundo - uma idéia atualmente exposta na mídia, no discurso político e popular e vinculada em contraponto à ampla propagação do ideal moderno de justiça social.

\footnotetext{
* M estre em economia pelo Instituto de Economia da UFRJ e pesquisador do IETS - Instituto de Estudos do Trabalho e Sociedade, Rio de Janeiro, rudirocha80@yahoo.com.br ou rudi@iets.org.br.; Professor do Instituto de Economia da UFRJ e diretor do IETS - Instituto de Estudos do Trabalho e Sociedade, aurani@iets.org.br. O s autores agradecem aos comentários e incentivos de Serguei Soares, Ricardo Paes de Barros, J oão Sabóia, Sonia R ocha, J oana Costa, Gabriel Ulyssea, Dimitri Szerman, A dalberto Cardoso, bem como de referees anônimos. Submetido: Fevereiro, 2006; aceito: A gosto, 2006.
} 
Uma breve pesquisa em arquivos de jornais de grande circulação no Brasil confirma a exposição do quadro de desigualdade de renda no país. $\mathrm{No}$ ano de 2005, o jornal O G lobo registrou 17 citações do termo "Gini" ou "Índice de Gini" e 116 matérias ou artigos trazendo a expressão "distribuição de renda", sendo a grande maioria referente ao caso brasileiro. Para o mesmo ano, os arquivos da Folha de São Paulo retornaram 249 matérias ou artigos contendo o termo "distribuição de renda" e 18 referências para "Gini" ou "Índice de Gini".

0 quadro de desigualdade de renda no Brasil, portanto, não apenas permeia as relações econômicas e sociais neste país, ou está presente em estatísticas oficiais e artigos acadêmicos, como também faz parte da carga de informação sistematizada e recebida freqüentemente pel os brasileiros. J untamente com os fatos, a mensagem da mídia e dos formadores de opinião, o quadro é invariavelmente crítico e aponta para o inevitável consenso: a desigualdade de renda brasileira é extrema e representa um mal a ser combatido.

$\mathrm{N}$ ão à toa, em recente pesquisa do ISSP (International Social Survey Programme, módulo de 1999) sobre percepções de desigualdade e opiniões sobre justiça distributiva, aplicada no Brasil e em mais de 20 países, os brasileiros se destacaram pela severidade com que avaliam a desigualdade de renda em seu próprio país. Cerca de $84 \%$ dos entrevistados no Brasil concordaram totalmente com a afirmativa de que "em seu país, as diferenças de renda são muito grandes" . Em nenhum outro país participante da pesquisa esta concordância total foi tão alta.

No entanto, apesar dessa alta desigualdade de renda ser uma evidência nacional, constantemente exposta pelos meios de comunicação e corroborada pelo discurso popular, este artigo traz as seguintes perguntas: os brasileiros, para além do discurso popular, conhecem de fato a realidade desigual em que vivem? Conhecem os mais básicos parâmetros da distribuição de renda no Brasil? Sabem quantos são, quanto ganham e como vivem os mais pobres ou os mais ricos neste país?

0 presente artigo consiste em um relato descritivo e empírico sobre o modo como os brasileiros se situam na escala social e de como percebem a distribuição de renda no país em que vivem. Ao longo deste relato, a hipótese central que se sustenta refere-se ao fato de que há um grande paradoxo entre o discurso popular aparentemente consciente sobre a desigualdade no Brasil e a realidade de desconhecimento acerca de como a renda é efetivamente distribuída no país.

Procura-se, ainda, discutir brevemente as possíveis causas e conseqüências deste desconhecimento. Por um lado, tendo em vista suas causas, mobilizam-se as noções de grupos de referência e da heurística da disponibilidade - os indivíduos tenderiam a construir imagens da estrutura social através da generalização de experiências próprias e da vivência pessoal, distorcendo a realidade a partir de grupos de referência homogêneos e mal delimitados. Por outro lado, com atenção às conseqüências, argumenta-se que tal quadro de desconhecimento não colabora no esforço em prol de menos pobreza e mais igualdade.

Este artigo está organizado em três seções, além desta introdução. N a próxima seção, investigam-se empiricamente como os brasileiros se posicionam na estrutura social e como eles percebem a distribuição de renda no país. É neste con- 
texto descritivo que se discute a hipótese central do trabalho. Para tanto, utilizam-se alguns itens da pesquisa do ISSP (1999) sobre percepção da desigualdade, cujos resultados são reforçados por outra pesquisa, mais direcionada àquela hipótese, embora de menor escopo, realizada entre estudantes do Instituto de Economia da Universidade Federal do Rio de Janeiro (IE-UFRJ). N a terceira seção, discutem-se possíveis causas e conseqüências do quadro empírico encontrado, enquanto que a última seção traz as considerações finais do trabalho.

\section{DISCURSO POPULAR, POSICIONAMENTO SOCIAL SUBJETIVO E A HIPÓTESE DA DISTRIBUIÇÃO DE REN DA DESCONHECIDA: UM A ANÁLISE EM PÍRICA}

\section{A presentação do ISSP (1999) e estratégia para análise empírica}

Este trabalho utiliza como principal base de dados a pesquisa do ISSP, módulo de 1999, uma contribuição para o entendimento das percepções de brasileiros e de outros cidadãos em mais de vinte países sobre o modo como suas respectivas sociedades são, estão ou deveriam ser ordenadas.

O ISSP (International Social Survey Programme) define-se como: “ ... a continuing annual program of cross-national collaboration on surveys covering important topics for social science research. It brings together pre-existing social science projects and coordinates research goals, thereby adding a cross-national, cross-cultural perspective to the individual national studies" . ${ }^{1} 0$ Programa existe desde o início dos anos 1980 e já implementou aproximadamente vinte pesquisas referentes a temas sociais, dentre elas, três relacionadas a percepções de desigualdade e justiça distributiva, elaboradas nos anos de 1987, 1992 e 1999. ${ }^{2}$ São 39 países membros do Programa, embora nem todos participem de todos os módulos. ${ }^{3} \mathrm{O}$ s temas e os questionários são avaliados e testados em um conjunto pequeno de países antes da rodada principal. A junção das bases em um banco de dados unificado é de responsabilidade da U niversidade de Colônia, Alemanha (Z entralarchiv für Empirische Sozialforschung, ZA ). Esta instituição é responsável também pelo zelo a regras de padronização metodológica.

As pesquisas sobre percepção de desigualdade social (módulos 1987, 1992 e 1999) trazem opiniões dos entrevistados sobre a estrutura social do país em qual vivem, sobre justiça distributiva, prioridades de políticas públicas, determinantes positivos e normativos de remunerações ao trabalho, mobilidade social, dentre

\footnotetext{
${ }^{1}$ www.issp.org.

${ }^{2}$ Existe um conjunto de perguntas comum aos três módulos, embora os questionários não sejam idênticos.

${ }^{3}$ O Brasil participou deste programa pela primeira vez em 1999, no terceiro módulo sobre percepções de desigualdade.
} 
outros itens. Juntamente com o Brasil, outros 26 países participaram do módulo ISSP (1999) - os europeus (do Leste e 0 este, com poucas exceções), os anglosaxões (EUA, C anadá, A ustrália e N ova Z elândia), Japão, Israel, Filipinas e os latino-americanos Brasil e C hile. As amostras são formadas em torno de 1000 a 2000 observações, nem todas representativas da população total de cada país. ${ }^{4} \mathrm{~A}$ pesquisa e, mais especificamente, os trabalhos de campo, foram implementados em diferentes anos a depender do país em questão, variando de 1999 a 2001 (por exemplo, 2001 para o caso brasileiro).

A companhando o aumento no número de países participantes do ISSP ao longo dos anos, a produção de estudos e a publicação de artigos e livros baseados nas pesquisas do programa vêm se tornando cada vez maiores. Grande parte dos trabalhos concentra-se sobre uma visão sociológica ou política do tema, sendo também predominante a abordagem empírica descritiva e comparativa entre países - na maioria dos casos, incluindo-se grupos pequenos de países e um grande número de itens do questionário. ${ }^{5}$

Tendo como foco principal o caso brasileiro, embora em uma perspectiva internacional comparada, destacaremos dois itens da pesquisa do ISSP (1999). 0 primeiro, por se tratar de uma pergunta qualitativa e estimulada acerca do formato da estrutura social, será associado por hipótese à carga de juízos e percepções imediatas que permeiam a essência do discurso popular sobre desigualdade. 0 segundo, mais central neste artigo, de onde se obtém o posicionamento social subjetivo dos respondentes e com o qual cruzamos referências de posicionamento objetivo na distribuição de renda brasileira, nos oferecerá um conjunto de informações derivadas, comparativas entre a realidade existente e a percepção dos entrevistados.

Como reforço à análise, na última parte desta seção, utiliza-se também outro conjunto de entrevistas sobre tópicos congêneres, realizadas por e sobre estudantes do Instituto de Economia da UFRJ (J unho de 2005). Essas entrevistas foram idealizadas eelaboradas com o objetivo particular de complementar a pesquisa do ISSP (1999) e testar o conhecimento sobre o tema de um público supostamente bem informado e com grau el evado de escolaridade 6 .

\section{O Desenho da Desigualdade e o D iscurso Popular}

0 primeiro item da pesquisa do ISSP (1999) aqui selecionado refere-se à imagem que as pessoas têm da configuração dos estratos sociais no país em que vi-

\footnotetext{
${ }^{4}$ Como é o caso de Áustria, Chile, França, Israel, Polônia, Rússia, Eslovênia e Estados Unidos.

${ }^{5}$ Para trabalhos já realizados no Brasil sobre esta base de dados, ver Scalon (2004) e R ocha (2004). Para uma descrição mais aprofundada sobre os métodos de amostragem, entrevistas, traduções de questionário e outros, ver ISSP (2003). Para mais informações sobre o programa e este módulo, acessar www.issp.org.
}

${ }^{6}$ Pesquisa coordenada pelos próprios autores. 
vem. M ais precisamente, os entrevistados escolhiam dentre cinco diagramas aquele que descrevesse mais fielmente 0 ordenamento social existente em seus respectivos países. A figura abaixo apresenta as opções de diagramas e destaca a pergunta presente no questionário da pesquisa.

Figura 1

Desigualdade em Diagramas

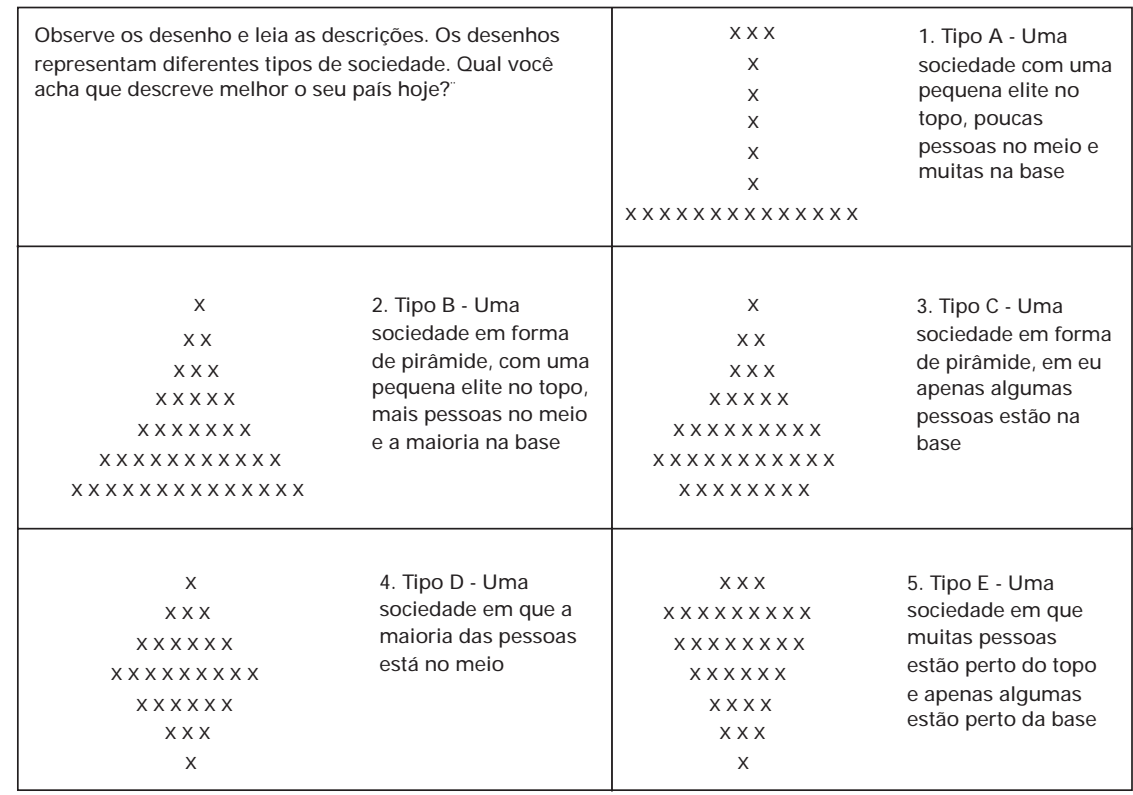

O bserva-se que os diagramas podem ser interpretados como representativos de sociedades com diferentes graus de desigualdade e formatos de estratificação. Verifica-se que o grau de desigualdade de renda diminui entre o diagrama A (o mais desigual e polarizado) e o diagrama $D$. No diagrama $A$, existe uma pequena elite no topo da pirâmide social, distante da maior parte da população, à base. 0 diagrama $\mathrm{D}$ lembra uma distribuição normal de probabilidade, com uma freqüência elevada de pessoas ao meio e limitada nos extremos. 0 diagrama $E$ apresenta um grau de desigualdade semel hante ao C, embora a estrutura social apareça invertida, com um pequeno número de pessoas à base.

Para empreender uma análise simplificada deste item, portanto, pressupõese que os diagramas são interpretados pelos entrevistados segundo uma ordem decrescente de desigual dade, do A ao E. Para cada país incluído na pesquisa, além das freqüências das respostas para cada uma das cinco categorias, estimou-se um indicador médio de "desigualdade observada" (ou visualmente perceptível). Este indicador foi construído a partir de uma ordenação dos digramas do número 1 ao 5 , sendo 1 o diagrama $E$, supostamente o menos desigual, 2 o diagrama $D$, e assim por diante, até a associação do número 5 ao diagrama $\mathrm{A}$, o mais desigual. Tomou-se então a média das respostas por país, não incluindo os entrevistados 
que não souberam ou não quiseram responder à questão. Uma média próxima a 5 corresponde, portanto, a uma desigualdade observada elevada. A próxima tabela traz os resultados?

Tabela 1

Desigualdade em Diagramas: Resultados

\begin{tabular}{|c|c|c|c|c|c|c|c|}
\hline Países & $\begin{array}{l}\text { esigualdade } \\
\text { Observada }\end{array}$ & $\begin{array}{c}\text { Tipo A } \\
\text { (5) }\end{array}$ & $\begin{array}{c}\text { Tipo B } \\
\text { (4) }\end{array}$ & $\begin{array}{c}\text { Tipo C } \\
\text { (3) }\end{array}$ & $\begin{array}{l}\text { Tipo D } \\
\text { (2) }\end{array}$ & $\begin{array}{c}\text { Tipo } E \\
(1)\end{array}$ & $\begin{array}{l}\text { Sem resposta } \\
\text { ou não soube } \\
\text { escolher (6) }\end{array}$ \\
\hline Australia & 3,17 & 0,09 & 0,32 & 0,24 & 0,31 & 0,01 & 0,03 \\
\hline Canadá & 3,30 & 0,18 & 0,22 & 0,29 & 0,27 & 0,01 & 0,03 \\
\hline EUA & 3,32 & 0,15 & 0,29 & 0,17 & 0,25 & 0,03 & 0,12 \\
\hline N. Zelândia & 3,70 & 0,18 & 0,33 & 0,25 & 0,19 & 0,01 & 0,04 \\
\hline Alemanha & 3,23 & 0,10 & 0,26 & 0,25 & 0,24 & 0,02 & 0,12 \\
\hline Austria & 3,00 & 0,08 & 0,24 & 0,25 & 0,36 & 0,02 & 0,06 \\
\hline Espanha & 3,21 & 0,07 & 0,33 & 0,24 & 0,22 & 0,03 & 0,13 \\
\hline França & 3,61 & 0,12 & 0,49 & 0,23 & 0,13 & 0,01 & 0,02 \\
\hline Noruega & 2,44 & 0,03 & 0,11 & 0,19 & 0,54 & 0,07 & 0,06 \\
\hline Portugal & 3,59 & 0,17 & 0,47 & 0,19 & 0,11 & 0,05 & 0,00 \\
\hline Suécia & 3,09 & 0,10 & 0,24 & 0,27 & 0,33 & 0,01 & 0,05 \\
\hline Brasil & 4,02 & 0,32 & 0,36 & 0,05 & 0,05 & 0,05 & 0,17 \\
\hline \multirow[t]{2}{*}{ Chile } & 3,96 & 0,27 & 0,46 & 0,11 & 0,07 & 0,02 & 0,07 \\
\hline & & 0,00 & 0,00 & 0,00 & 0,00 & 0,00 & 0,00 \\
\hline Filipinas & 3,03 & 0,25 & 0,29 & 0,11 & 0,20 & 0,12 & 0,03 \\
\hline Israel & 3,36 & 0,21 & 0,33 & 0,23 & 0,19 & 0,02 & 0,02 \\
\hline J apão & 3,52 & 0,06 & 0,29 & 0,20 & 0,32 & 0,03 & 0,10 \\
\hline Bulgária & 4,59 & 0,65 & 0,21 & 0,04 & 0,02 & 0,01 & 0,07 \\
\hline Eslováquia & 4,29 & 0,51 & 0,32 & 0,07 & 0,05 & 0,02 & 0,03 \\
\hline Eslovênia & 3,51 & 0,28 & 0,24 & 0,17 & 0,22 & 0,05 & 0,05 \\
\hline Hungria & 4,41 & 0,57 & 0,24 & 0,05 & 0,04 & 0,02 & 0,07 \\
\hline Letônia & 4,52 & 0,66 & 0,23 & 0,05 & 0,04 & 0,01 & 0,02 \\
\hline Polônia & 4,22 & 0,49 & 0,16 & 0,08 & 0,07 & 0,03 & 0,17 \\
\hline Rep. Tcheca & a $\quad 3,81$ & 0,30 & 0,35 & 0,18 & 0,12 & 0,02 & 0,03 \\
\hline Russia & 4,51 & 0,59 & 0,18 & 0,05 & 0,03 & 0,01 & 0,13 \\
\hline
\end{tabular}

Fonte de dados: ISSP (1999)

Nota: A soma das porcentagens $(1)+(2)+(3)+(4)+(5)+(6)=100 \%$

${ }^{7}$ O s países seguem agrupados conforme localização geográfica ou afinidade sócio-cultural. Japão, Filipinas e Israel foram agrupados em um único conjunto que pode ser denominado por "outros". 
A lguns fatos estilizados podem ser destacados a partir dos números acima. Por exemplo, em algumas sociedades consideradas de fato mais igualitárias (em termos de renda, segundo o índice de Gini), grande parcela dos entrevistados escolheu o diagrama $D$, ou seja, aquele que representa uma estrutura social também mais igualitária, com elevada freqüência de pessoas ao centro - este é o caso dos noruegueses ( $54 \%$ ), suecos (33\%), japoneses (32\%) e austríacos (36\%). Por outro lado, em países com distribuições de renda mais desiguais, como Rússia, Chile ou mesmo o Brasil, os respondentes escolheram predominantemente os diagramas A e B.

À exceção desta correlação positiva entre a desigualdade de renda medida e observada, nos EUA, 28\% dos entrevistados escolheram o diagrama $D$ ou o $E$ (neste país, o índice de G ini ultrapassa a marca de 0.40 ). N a N ova Z elândia (Índice de Gini de 0.44 ) este número chegou a $20 \%$, nas Filipinas (G ini de 0.46 ), $32 \%$. N os países do Leste Europeu, em especial, a desigualdade observada mostrou-se bastante elevada - como é o caso da Eslováquia (mais da metade dos respondentes escolheram o diagrama $A$, enquanto que 0 índice de $G$ ini não é superior a 0.20 ) e Bulgária (respectivamente, $65 \%$ e 0.28 ). Se excluídos da análise os países do Leste Europeu, temos que uma correlação entre a desigualdade de renda medida (Índice de Gini) e o indicador de desigualdade observada mostrase positiva e el evada (0.81), como segue ilustrado abaixo no gráfico de dispersão entre as duas variáveis.

\section{Gráfico 1}

Correlação entre o Índice de Gini e o Indicador de Desigualdade Observada

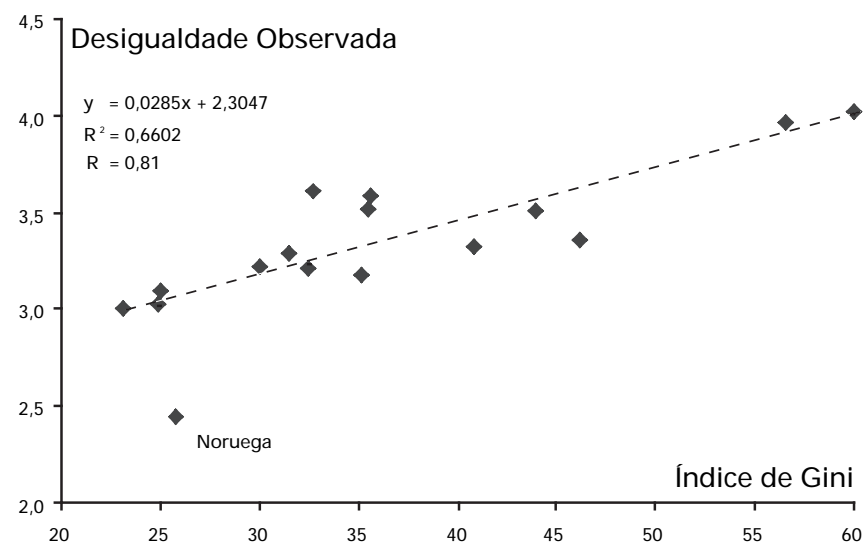

Fonte de Dados: Banco Mundial (2000) e ISSP (1999) Nota: Excluindo países do Leste Europeu

N o gráfico está indicado que o Brasil encontra-se exatamente sobre o ponto que representa ao mesmo tempo a maior desigualdade de renda medida e observada. Em princípio, de acordo com a pesquisa, a imagem que os brasileiros têm da estratificação da sociedade no país, em média, é de uma pirâmide social com 
um pequeno número de pessoas ao topo e crescente nesta freqüência em direção à base - apresentando um indicador médio de desigualdade observada igual a 4.02, o que se pode associar ao diagrama B. Enfim, embora mais de $30 \%$ dos entrevistados no Brasil tenham escolhido os diagramas mais igualitários ou tenham se abstido da escolha, quando comparados aos respondentes dos demais países incluídos na análise, pode-se dizer que os brasileiros apresentaram um padrão severo de avaliação de sua estrutura social.

No entanto, em contrapartida ao conjunto de resultados acima apresentado, questiona-se até que ponto a estrutura e a estratificação social percebidas pelos entrevistados brasileiros correspondem-se de maneira fiel àquelas de fato existentes no país. O u melhor, para além de uma pergunta qualitativa e estimulada sobre o tema, quais seriam as referências de avaliação da estrutura e da estratificação social no país acionadas pelos entrevistados brasileiros? Q ual seria a percepção destes, por exemplo, da distância entre a base e o topo dos diagramas escolhidos? 0 que os entrevistados consideram ser o meio da sociedade? Enfim, para os brasileiros, como o status social ou a renda estariam distribuídos no país em que vivem? Para responder estas questões, é necessário utilizar um elo de conexão entre realidade e representação subjetiva da sociedade.

\section{Percepções sobre Posicionamento Social: R icos? Pobres? D esiguais?}

Em um dos itens do questionário do ISSP (1999), o entrevistado escolhia, em uma escala de 1 a 10 (base ao topo), a categoria que melhor correspondesse à sua respectiva localização no ordenamento social. ${ }^{8}$ Esta percepção de posicionamento nos permite não apenas conhecer o modo como o entrevistado se percebe na escala social, como também interpretar aspectos de sua representação acerca da própria estrutura social vigente no país. Tal fato é possível a partir do momento em que é possível cruzar posições percebidas e reais, utilizando como elo conectivo a distribuição objetiva de renda domiciliar per capita do país. ${ }^{9}$

A análise partirá do suposto de que o posicionamento percebido do respondente na escala social traz uma informação derivada. A o responder à questão, tendo em vista uma escala crescente em renda ou status social, o entrevistado deixa indicada sua percepção acerca das densidades populacionais que estariam acima e abaixo de um parâmetro quantitativamente conhecido, i.e., sua própria renda familiar ou domiciliar per capita. Assim, pressupõe-se que quanto maior a

\footnotetext{
${ }^{8} \mathrm{O}$ item do questionário era acompanhado por uma figura em forma de coluna, dividida em dez unidades. $\mathrm{M}$ ais precisamente, a pergunta era a seguinte: "N a sociedade brasileira há grupos que tendem a estar no topo da escala social e grupos que tendem a estar na base. A baixo está uma escala que vai do topo à base, em que ponto 1 corresponde ao topo da escala e o ponto 10 à base da escala. Em sua opinião, onde é que o sr(a) acha que está na seguinte escala?".

${ }^{9}$ Chama-se atenção para o fato de que embora o item do questionário não mencione o termo "renda" em sua pergunta, parte-se do pressuposto de que esta variável é em grande medida determinante na interpretação do entrevistado à pergunta.
} 
distância entre o posicionamento real e o subjetivo, também maior o grau de desconhecimento do entrevistado em relação aos parâmetros básicos da distribuição de renda no país (renda média, mediana e dispersão), maior o grau de subestimação/superestimação da pobreza ou da riqueza e maior o grau de desconhecimento acerca das diferenças de renda na sociedade.

A ssim, partindo-se da interpretação acima e utilizando os dados da PN AD (Pesquisa N acional de A mostragem Domiciliar, IBGE - 2001) e do ISSP (1999), segue na próxima tabela o cruzamento entre os posicionamentos objetivo e percebido dos entrevistados brasileiros na escala social sugerida.

Tabela 2

Cruzamento entre posições percebidas e objetivas

\begin{tabular}{|c|c|c|c|c|c|c|c|c|c|c|c|c|c|}
\hline \multicolumn{2}{|c|}{ Posição Objetiva (PNAD - 2001) } & \multirow{2}{*}{$\begin{array}{c}\text { Posição } \\
\text { Média }\end{array}$} & \multicolumn{10}{|c|}{ Posição Percebida (ISSP - 1999/2001) } & \multirow{2}{*}{ Soma } \\
\hline \multicolumn{2}{|c|}{$\begin{array}{c}\text { Décimos da Distribuição } \\
\text { de Renda (R\$) }\end{array}$} & & Base & 2 & 3 & 4 & 5 & 6 & 7 & 8 & 9 & Topo & \\
\hline $10 \%$ Mais Pobres & $0-42$ & 3,4 & 31,4 & 19,6 & 11,3 & 7,7 & 6,7 & 6,7 & 4,1 & 6,7 & 5,2 & 0,5 & 100 \\
\hline 2 & $43-69$ & 3,4 & 24,5 & 16,4 & 20,9 & 11,8 & 7,3 & 8,2 & 3,6 & 3,2 & 2,7 & 1,4 & 100 \\
\hline 3 & $70-100$ & 3,8 & 20,5 & 12,7 & 19,9 & 14,3 & 11,4 & 7,2 & 5,2 & 4,2 & 2,3 & 2,3 & 100 \\
\hline 4 & $101-134$ & 3,7 & 17,6 & 15,0 & 22,2 & 13,7 & 7,8 & 9,8 & 7,8 & 2,6 & 2,6 & 0,7 & 100 \\
\hline 5 & $135-174$ & 3,7 & 13,9 & 10,4 & 25,4 & 22,0 & 11,6 & 12,1 & 2,3 & 0,6 & 1,2 & 0,6 & 100 \\
\hline 6 & $175-230$ & 3,7 & 14,9 & 12,9 & 23,7 & 16,5 & 14,9 & 6,7 & 6,2 & 3,1 & 1,0 & 0,0 & 100 \\
\hline 7 & $231-301$ & 3,6 & 9,4 & 17,1 & 27,1 & 15,3 & 17,1 & 8,8 & 4,7 & 0,0 & 0,6 & 0,0 & 100 \\
\hline 8 & $302-433$ & 4,1 & 13,7 & 6,9 & 19,1 & 22,9 & 9,9 & 20,6 & 1,5 & 3,8 & 0,8 & 0,8 & 100 \\
\hline 9 & $434-750$ & 4,4 & 9,9 & 4,1 & 18,2 & 21,5 & 11,6 & 23,1 & 10,7 & 0,0 & 0,8 & 0,0 & 100 \\
\hline $10 \%$ Mais Ricos & $750-\max$ & 4,6 & 10,8 & 9,2 & 12,3 & 18,5 & 10,8 & 15,4 & 15,4 & 3,1 & 0,0 & 4,6 & 100 \\
\hline \multicolumn{2}{|l|}{$\mathrm{N}$} & & 311 & 228 & 354 & 270 & 188 & 182 & 93 & 51 & 34 & 17 & 1728 \\
\hline \multicolumn{2}{|l|}{$\%$ coluna } & & 18,0 & 13,2 & 20,5 & 15,6 & 10,9 & 10,5 & 5,4 & 3,0 & 2,0 & 1,0 & 100 \\
\hline
\end{tabular}

Nota: Posição objetiva calculada a partir dos dados de renda domiciliar per capita incluídos na pesquisa do ISSP (1999) e cruzados com os décimos da distribuição objetiva de renda domiciliar per capita brasileira a partir da PNAD (2001). Relembrando que, Fontes de dados: IBGE/PNAD (2001) e ISSP (1999).

A tabela acima nos permite verificar uma relação fraca entre o posicionamento social real e o percebido pelos entrevistados brasileiros. Em média, estes se situaram entre o terceiro e o quarto décimos da escala. A posição média estimada ficou em 3.7, sendo 4.6 entre os $10 \%$ mais ricos e 3.4 entre os $10 \%$ mais pobres. Cerca de $5.7 \%$ dos entrevistados situados objetivamente entre os $10 \%$ mais pobres se localizaram subjetivamente nos dois décimos mais altos, enquanto que apenas $4.6 \%$ dos $10 \%$ mais ricos assim o fizeram. $M$ etade dos $10 \%$ mais ricos se posicionou entre as quatro categorias mais baixas da escala. Para toda a amostra, a moda da freqüência de respostas ficou sobre o terceiro décimo inferior.

$O \mathrm{~s}$ resultados acima trazem duas informações correlatas. Em primeiro lugar, de imediato, que os entrevistados brasileiros erram ao se posicionarem na escala social e que tendem a se perceber, em média, relativamente mais pobres do que 
de fato são. Em segundo lugar, que mostram desconhecer parâmetros básicos da distribuição de renda brasileira, como, por exemplo, a mediana e os quantis/decis. M ais do que isso, ao se posicionarem em média abaixo do quinto décimo, demonstram não incluir em suas percepções grande parcela da população localizada à base da escala social.

Como corolário destes fatos estilizados, temos que a pobreza é subrepresentada pelos brasileiros, especialmente aqueles mais ricos. Um indivíduo localizado objetivamente no 9 o decil da distribuição de renda e que se posicionou subjetivamente entre os $30 \%$ mais pobres revela perceber que apenas $30 \%$ da população brasileira (ou menos) têm status econômico efetivo inferior ao 9o decil de renda. Por outro lado, seguindo a mesma interpretação, mas em sentido contrário, a apropriação de renda dos estratos mais ricos da população é subrepresentada por aqueles que se localizam efetivamente à base da distribuição de renda, mas que se percebem em décimos superiores a esta base.

A desigualdade de renda (ou status econômico) percebida pelos entrevistados não parece guardar relação próxima àquela efetivamente existente no país, 0 que se comprova pela distorção na percepção de parâmetros distributivos básicos, como média e mediana. O u seja, embora exista no discurso popular o reconhecimento de que a desigualdade de renda é muito elevada, verificou-se que os entrevistados brasileiros em grande medida desconhecem o modo como a renda ou o status econômico são efetivamente distribuídos no país. 0 fato dos entrevistados situados em décimos superiores da escala social subrepresentarem a pobreza e sobreestimarem a mediana da distribuição de renda fortalece a hipótese de que a magnitude das diferenças de renda no Brasil e da razão entre os percentuais de renda apropriados pelos mais ricos e pelos mais pobres, em realidade, pode estar sendo subestimada por parte significativa da população. ${ }^{10}$

\section{Comparação Internacional}

A análise de outros países incluídos na pesquisa do ISSP (1999) mostra que o fenômeno de desvio de posicionamento social evidenciado anteriormente para o caso brasileiro, embora relativamente mais forte, não é exclusivo deste país. Utilizando os dados de renda domiciliar per capita da própria pesquisa, replicouse a investigação anterior em relação a um conjunto de países selecionados Alemanha, EUA, N oruega, Japão, R epública T checa, Rússia e Brasil. ${ }^{11}$

O bservou-se que, de modo geral, existe uma clara tendência de posiciona-

\footnotetext{
${ }^{10} \mathrm{~N}$ este caso, por subrepresentação da pobreza compreende-se a exclusão das percepções de parcela da população localizada à base da distribuição de renda ou, ao menos, localizada abaixo da posição objetiva do entrevistado.

${ }^{11}$ A seleção deste grupo de países respeitou dois critérios: (i) a disponibilidade de dados sobre renda domiciliar per capita da pesquisa e; (ii) a heterogeneidade sócio-cultural. Para fins de comparação, também se utilizou, no caso brasileiro, os dados de renda da pesquisa do ISSP, não os dados da PN AD.
} 
mento dos entrevistados ao centro da escala social, sendo muito pequena a freqüência de respostas relativas aos décimos extremos - topo e base. Como ilustração, o gráfico a seguir mostra as estimativas do posicionamento social percebido médio, para três grupos de entrevistados em cada um dos países selecionados: (i) Base: grupo de entrevistados localizados objetivamente em um dentre os três décimos inferiores da distribuição de renda domiciliar per capita; (ii) M édia: entrevistados localizados objetivamente entre o quarto e o sétimo décimos (incluindo ambos) e; (iii) Topo: entrevistados localizados objetivamente em um dentre os três décimos superiores da distribuição de renda domiciliar per capita.

\section{Gráfico 2}

Percepção de Posicionamento Social: Média por Três Grupos de Renda em Países Selecionados

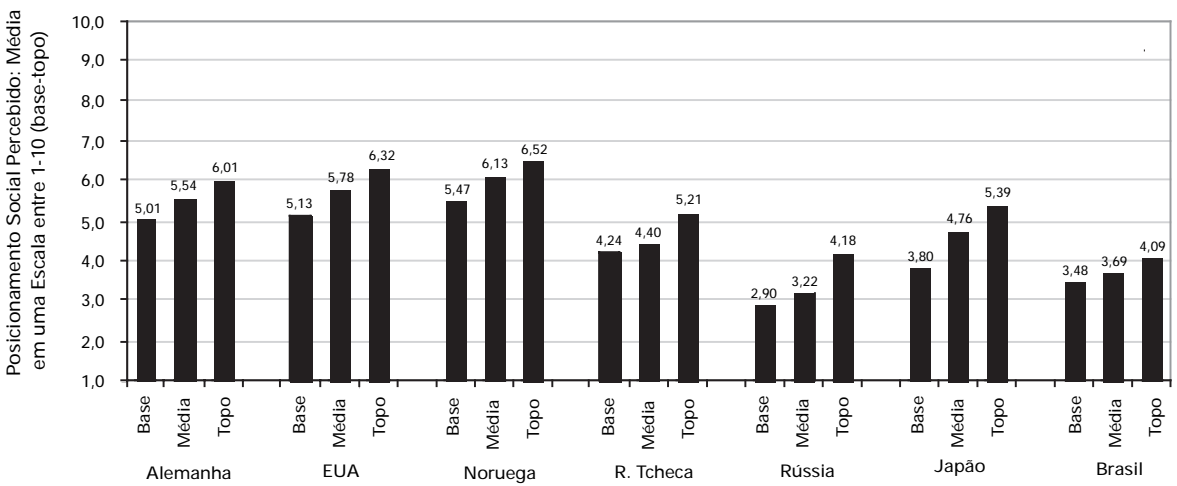

Posicionamento Social Objetivo por Três Grupos de Renda em Países Selecionados

Fonte de Dados: ISSP (1999)

O bserva-se que o caso brasileiro é similar ao russo, em que grande parcela dos entrevistados posicionou-se na metade inferior da escala social. O s alemães, os norte-americanos e os noruegueses apresentaram padrões de respostas semeIhantes entre si; nestes países os respondentes mais ricos localizaram-se, em média, na metade superior da escala e, os mais pobres, na metade inferior. O s japoneses e tchecos apresentaram um padrão de posicionamento intermediário aos demais casos; entretanto, sinalizaram com uma percepção mais pessimista em relação ao posicionamento na escala social; em média, em sua metade inferior.

Se válido o pressuposto mencionado anteriormente, portanto, os resultados deste gráfico indicam que o desconhecimento em relação ao modo como a renda é distribuída na população não é fato característico apenas entre os brasileiros, mas também, parece generalizar-se entre os respondentes de outros países. Em outra ilustração, os gráficos abaixo apresentam uma análise comparativa entre as respostas dos entrevistados mais ricos (localizados objetivamente no décimo superior da distribuição de renda domiciliar per capita) e mais pobres (nos dois décimos inferiores) no Brasil e na N oruega, país cujo indicador médio de percepção de posicionamento social é o mais elevado. 
Gráficos 3

Percepção de Posicionamento: Brasil vs Noruega
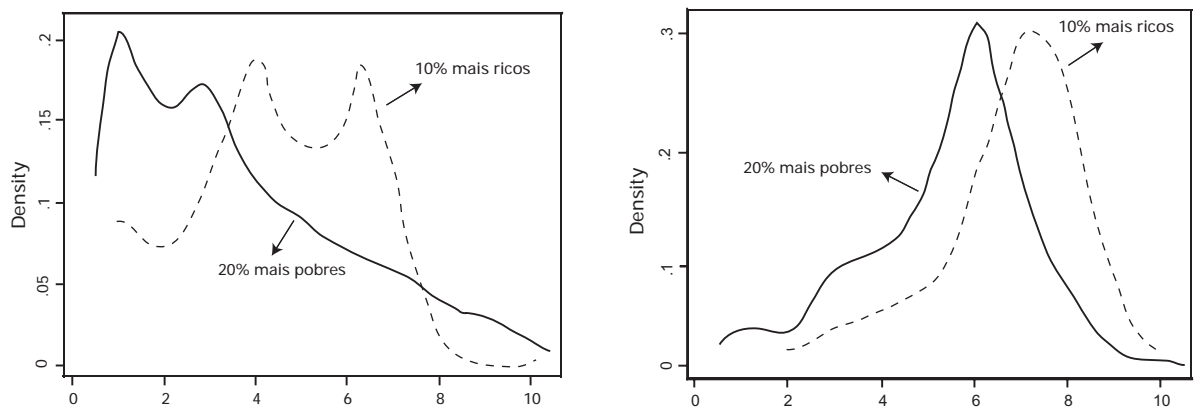

Fonte de Dados: ISSP (1999)

O s gráficos acima são interessantes no que tange às percepções de posicionamento dos brasileiros (gráfico à esquerda) em comparação a outros respondentes de um país com baixa desigualdade e alto nível de desenvolvimento humano, como a N oruega (gráfico à direita). Embora pareça existir uma tendência dos entrevistados se posicionarem mais ao centro da escala social, como observado, por exemplo, entre os noruegueses mais ricos, fica claro que no caso brasileiro o desvio entre posição real e percebida é mais acentuado. 0 s resultados indicam que a parcela mais rica da população brasileira percebe-se relativamente empobrecida, o oposto do que ocorre com os noruegueses mais pobres, que se percebem em grande medida na metade superior da escala.

\section{A Pesquisa entre os Estudantes de Economia: R eforços ao Argumento}

Com o objetivo de levantar informações mais específicas sobre a questão do conhecimento e percepção dos brasileiros acerca da distribuição de renda no país, aplicou-se um questionário em uma amostra representativa de 121 alunos do Instituto de Economia da Universidade Federal do R io de Janeiro (IE-UFRJ). Esta pesquisa é relevante por três razões. Em primeiro lugar, ao se supor que os alunos entrevistados pertencem a um grupo de brasileiros que figuram entre os mais bem informados do país. Em segundo lugar, a grande maioria dos entrevistados faz parte da elite econômica brasileira, localizando-se com freqüência entre os $10 \%$ mais ricos do país (a renda domiciliar per capita média dos entrevistados ficou em $R \$ 1.868$ ). Por final, justamente na véspera do início das entrevistas, 0 IPEA (Instituto de Pesquisa Econômica A plicada) divulgou o documento Radar Social (IPEA, junho de 2005), de ampla repercussão na mídia impressa e televisiva, contendo variados dados sobre pobreza e desigualdade no Brasil.

Alguns dos resultados encontrados são os seguintes. Q uando perguntados sobre qual seria o valor do salário mínimo vigente, $20 \%$ dos alunos responderam incorretamente (a média ficou em $R \$ 292$, em contraste com o valor correto de $R \$ 300)$. Do ponto de vista normativo, para os estudantes, o salário mínimo no Brasil deveria ser, em média, de R \$ 605 e a linha de pobreza, em termos de renda familiar per capita, de $\mathrm{R} \$ 301$. N estes termos, utilizando os dados de ren- 
da domiciliar per capita da PN AD (2003), teríamos no Brasil cerca de $64 \%$ de domicílios vivendo abaixo desta linha de pobreza - ou seja, aproximadamente 108 milhões de brasileiros.

Q uando perguntados, "qual é, a seu ver, o intervalo de renda familiar per capita que define a classe média no Brasil" , os estudantes retornaram, em média, os valores de $R \$ 1.388$ a $R \$ 5.002$ - o que, ainda segundo os dados da PN AD (2003), significa que apenas $4.7 \%$ da população fariam parte da classe média brasileira: temos acima de $R \$ 1.388$ cerca de $5.1 \%$ da população e apenas $0.4 \%$ acima de $R \$ 5.002$. O u seja, a renda domiciliar per capita das pessoas que fariam parte da classe média associa-se a estratos de renda relativamente altos, se considerada a distribuição objetiva de renda domiciliar per capita no país, cuja média ef etiva é de $R \$ 408$, a mediana, $R \$ 207$, e a moda, $R \$ 345$.

D estacam-se agora os resultados referentes à pergunta " qual você imagina que seja a participação na renda total (em \% ) de cada um dos décimos da distribuição da renda familiar per capita no Brasil?". Elaborou-se esta questão seguindo o objetivo específico de estimação de uma Curva de Lorenz e de um Índice de Gini percebidos.

D e modo geral, os estudantes entrevistados tiveram dificuldades em responder à questão. Cerca de $55 \%$ deles não respeitaram o fato de que a porcentagem de apropriação da renda total deve aumentar conforme nos movemos do primeiro e mais pobre décimo da distribuição ao último e mais rico; foi comum encontrar, por exemplo, Índices de Gini negativos. Assim, excluídos estes casos e restando apenas 54 observações cujas respostas respeitavam a relação esperada entre a distribuição acumulada da população e de renda, estimou-se um Índice de Gini percebido individualizado e a média do percentual apropriado por cada décimo da escala de renda. 0 s resultados seguem na figura abaixo.

Figura 2

Desigualdade Medida e Percebida em Curvas de Lorenz

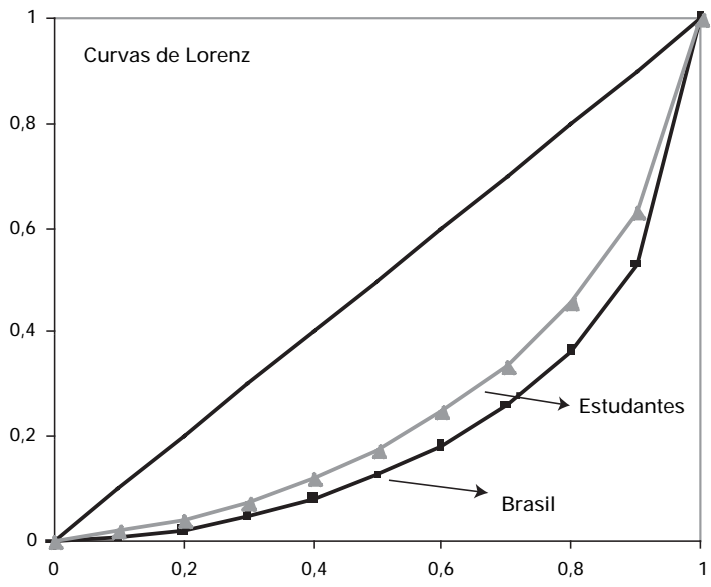

\begin{tabular}{ccc}
\hline \multicolumn{3}{c}{$\%$ de Apropriação da Renda } \\
\hline Décimos & Alunos & Brasil \\
\hline 1 & 0,020 & 0,007 \\
2 & 0,025 & 0,016 \\
3 & 0,032 & 0,025 \\
4 & 0,043 & 0,033 \\
5 & 0,055 & 0,046 \\
6 & 0,071 & 0,057 \\
7 & 0,091 & 0,076 \\
8 & 0,116 & 0,104 \\
9 & 0,179 & 0,163 \\
10 & 0,369 & 0,471 \\
\hline Gini & 0,479 & 0,574 \\
\hline
\end{tabular}

Fonte de Dados: Pesquisa IE/UFRJ e PNAD (2004) 
0 Índice de Gini percebido pelos estudantes que responderam de maneira coerente à questão ficou, em média, em 0.48 . Para estes alunos, os $10 \%$ mais ricos no Brasil apropriam-se de cerca de $37 \%$ da renda total, enquanto que os $50 \%$ mais pobres, de quase $20 \%$. Se considerados os dados da PN AD (2003), vemos que o Índice de Gini brasileiro fica em $0.57,,^{12}$ os $10 \%$ mais ricos apropriam-se de $47 \%$ da renda total e, os $50 \%$ mais pobres, de apenas $12.8 \%$.

\section{POSSÍVEIS CAUSA SE CON SEQÜÊN CIAS DA DISTRIBUIÇÃO DE RENDA DESCONHECIDA}

\section{Interpretando o D esconhecimento via G rupos de R eferência}

A percepção das pessoas sobre a posição que lhes cabe na escala social é uma questão central nas ciências sociais. Para os marxistas, a sociedade capitalista e 0 modo pelo qual se organiza a produção fazem com que os trabalhadores se reconheçam como pertencentes da base da escala social e, os capitalistas, ao topo desta. 0 crescimento econômico ao longo do tempo aprofunda a dicotomia entre base e topo, o que colabora para a polarização cada vez maior da sociedade em duas classes sociais. A mesma hipótese de que circunstâncias objetivas do padrão de vida das pessoas traduzem-se diretamente em percepções subjetivas é compartiIhada por Durkheim. Para este autor, no entanto, a urbanização, as mudanças na qualificação dos trabalhadores, o crescimento populacional e da economia levam à formação de uma estrutura social distinta, com uma freqüência relativa maior de pessoas ao centro da hierarquia social, poucos à base e poucos ao topo. ${ }^{13}$

Em contraste, a hipótese dos grupos de referência argumenta que a percepção individual acerca do formato da estrutura social e da posição nesta do próprio indivíduo é apenas fracamente relacionada às circunstâncias reais da sociedade. ${ }^{14} \mathrm{~N}$ esta perspectiva, as percepções sobre a estrutura social e sobre 0 posicionamento do indivíduo na escala social são particularmente formadas pe-

\footnotetext{
12 Índice de Gini calculado sobre a porcentagem apropriada de renda por cada décimo da população, assim como estimado para os estudantes. O IPEA (2005) estima este índice para o Brasil em 0.60.

${ }^{13} \mathrm{M}$ arx e Engels (1948), M arx (1867) e Durkheim (1933).

${ }^{14}$ Stouffer et al. (1949). $\mathrm{O}$ conceito de grupos de referência foi primeiramente trabalhado por $\mathrm{H}$ yman (1942) e Stouffer et al. (1949), não obstante ao fato de que a idéia já fosse discutida pela psicologia social. N o entanto, foi associado à noção de privação relativa que o conceito se popularizou, em especial, a partir do trabalho seminal de Runciman (1966, ver capítulo 2). A penas a partir de meados dos anos 1970 surgem estudos na economia que utilizam com maior centralidade a noção de grupos de referência: Sen (1976 e 1981), para a construção de medidas de pobreza; Y itzhaki (1979), H ey e Lambert (1980), Chakravarty e Chakraborty (1984) e Berrebi e Silber (1985), Stark e Taylor (1991), Podder (1996) e Duclos e Gregoire (2003), para a derivação de um índice de privação relativa. A demais, correlata ao tema, existe vasta literatura baseada na questão da utilidade relativa - ver, por exemplo, Clark e O swald (1996), A kerlof e Yellen (1990), Boskin e Sheshinski (1978), Kapteyn e Van Herwaarden (1980).
} 
las experiências e círculo de relações pessoais constituídas pelo próprio indivíduo a partir de um grupo de referência. Este seria um caso particular da heurística da disponibilidade, i.e., a tendência do indivíduo em construir a imagem de determinada estrutura social a partir da generalização de experiências pessoais restritas a imagens de seu cotidiano.

A interpretação deste viés perceptivo entre realidade e representação social pode ser enriquecida a partir da definição de cognição em D osi, M arengo e Fagiolo (1996, pp. 10-11):

“... cognition (...) is the process by which decision makers form and modify representations in order to make some sense of a reality which is generally too complex and uncertain to be fully understood. $\mathrm{H}$ ence, the necessity to acknowledge the existence (and persistence) of a systematic gap between the agents' cognitive abilities and reality..."

U ma das formas de desvio (gap) freqüentemente encontrada, dizem os autores, seria o que se chamou de desvio de conhecimento (knowledge gap) - o que envolve representações do ambiente sócio-econômico incompletas, vagas ou, simplesmente, erradas. ${ }^{15}$

N a mesma direção, segundo Denzau e N orth (1994) e N orth (1996), o sistema cognitivo é a estrutura pela qual os indivíduos receberiam e interpretariam a informação difusa deste ambiente sócio-econômico. Tal estrutura se constitui em duas dimensões. A primeira é genética, sobre a qual se desenvolve a segunda, formada por experiências pessoais. Por sua vez, classifica-se esta última em dois grupos: as experiências advindas ou do ambiente físico ou do sócio-cultural. O u seja, a representação de um ambiente complexo seria função da informação recebida e interpretada individualmente através de um sistema estruturado sobre uma arquitetura genética e por experiências pessoais.

Integrando estes conceitos à discussão sobre grupos de referência, tal representação do ambiente sócio-econômico pode ser interpretada enquanto um fenômeno originado inicialmente da observação e absorção individual da realidade distributiva intra-grupos de referência e do desconhecimento acerca do que se passa além de suas fronteiras. Entre a realidade distributiva na população e aquela que faz parte apenas de um grupo de referência não representativo daquela realidade existiria, portanto, um desvio de conhecimento.

Em síntese, sendo a distribuição de renda parte relevante do ambiente sócioeconômico, a delimitação de grupos de referência ou a representação de cada indivíduo acerca do formato da distribuição de renda e do seu respectivo grau de

${ }^{15}$ Dosi, M arengo e Fagiolo (1996) fazem uma resenha teórica extensa sobre problemas cognitivos e aprendizagem na economia, destacando os principais fatos estilizados. $O$ utras referências nesta literatura são M argolis (1987), Johnson-Laird (1983), M ayer (1992), Clark (1993), D enzau e N orth (1994), N orth $(1995,1996)$ e Holland et al. (1986). 
desigualdade seriam provenientes, portanto, do sistema de cognição interpretativo e classificatório pessoal. Limites de cognição e a complexidade e a heterogeneidade do ambiente físico e sócio-cultural são fatores que explicariam a existência de desvios de conhecimento em relação à forma como a renda é distribuída em determinada população.

Pode-se qualificar melhor a discussão sobre grupos de referência considerando-se a hipótese de amostragem subjetiva, o que explicaria a tendência dos indivíduos em se localizarem subjetivamente ao centro da escala social. ${ }^{16} \mathrm{D}$ e acordo com esta hipótese, um viés perceptivo é formado com base no meio social imediato do indivíduo, implicando na superestimação do número de pessoas similares a ele. ${ }^{17}$ Assim, 0 argumento completa-se a partir do momento em que se supõem grupos de referência homogêneos. Tal fato distorceria a amostra subjetiva do ambiente social formada pelo indivíduo, a qual seria projetada incorretamente como a verdadeira imagem da estrutura social e sobre a qual o indivíduo formaria suas percepções acerca de seu posicionamento social. Segundo Evans e K elley $\left(2004\right.$, p.6): ${ }^{18}$

"The subjective sampling hypothesis is really a blend of two hypotheses - first that people develop perceptions and self-images in light of reference groups (...), and, second, that reference groups are fairly homogeneous with respect to social class. (...) This homogeneity means that most people are objectively towards the middle of their reference groups. This objective centrality encourages people to see themselves as middle status".

Com a finalidade de discutir o conceito de grupos de referência e associá-lo à hipótese da desigualdade desconhecida, o presente artigo apóia-se na seguinte ilustração. D efine-se o grupo de referência de um indivíduo $X$ como um conjunto de $n$ outros indivíduos de determinada população cujas rendas ou outros atributos sócio-econômicos são percebidos e identificáveis pelo indivíduo X. N este caso, o indivíduo não é capaz de identificar a renda ou status econômico ou mesmo captar a existência de outros indivíduos que não façam parte de seu grupo de

\footnotetext{
${ }^{16}$ Evans e Kelley (2004).

${ }^{17}$ Woelfel e H aller (1971), Kahneman et al (1982) e Evans e Kelley (2004).

${ }^{18}$ O s trabalhos de Evans e K elley (K elley e Evans, 1995; e Evans e K elley, 2004) sobre este tema são particularmente relevantes pelo fato de utilizarem a pesquisa do ISSP (1999) aplicada a uma amostra grande de países (não incluindo o Brasil) e o item de posicionamento social como base empírica - até o momento, os autores constituem a mais completa referência sobre o tema associada à utilização deste item. A tese central dos autores sustenta que o posicionamento social subjetivo dos indivíduos é duplamente determinado a partir de uma conjunção entre circunstâncias objetivas (como o status econômico e social efetivo) e a hipótese dos grupos de referência. Esta dupla determinação levaria as pessoas a posicionarem-se ao centro da escala social, embora respeitando um viés em direção às respectivas posições objetivas. No entanto, nestes estudos, não obstante o foco dos autores estivesse especificamente sobre a sustentação de tal hipótese, sob um ponto de vista estritamente sociológico, não levaram em consideração informações sobre remuneração ou distribuição de renda e restringiramse apenas a uma análise agregada dos dados.
} 
referência. M ais precisamente, defina o grupo de referência de um indivíduo como um vetor das remunerações associadas aos seus integrantes. A penas como exemplo, tome uma cidade dividida em dois bairros distintos, um que chamaremos de bairro dos pobres e outro, bairro dos ricos. Suponha que em cada bairro habitem quatro moradores, e que a distribuição de renda no bairro dos pobres seja hipoteticamente $(2,4,4,6)$ e no bairro dos ricos $(8,16,16,36)$.

A nalisemos dois casos distintos. $\mathrm{N}$ o primeiro, os dois bairros da cidade localizam-se muito distantes um do outro, o que acarreta na delimitação de dois grupos de referência diferentes na mesma população, um circunscrito aos ricos e outro aos pobres. 0 s ricos identificam-se e percebem-se reciprocamente, reconhecem seus pares e a distribuição de renda de seu grupo, mas desconhecem a existência dos mais pobres; o mesmo ocorre no bairro dos pobres. No segundo caso, o bairro dos ricos e o bairro dos pobres convivem lado a lado, o que leva à delimitação de um único grupo de referência idêntico à população total da cidade. A gora, mesmo o mais pobre dos pobres percebe a existência e identifica a renda do mais rico dos ricos. Como ilustração deste exemplo, a figura abaixo representa graficamente as Curvas de Lorenz de cada um dos bairros e também de toda a população. ${ }^{19}$

\section{Figura 3}

A Cidade Partida em Curvas de Lorenz

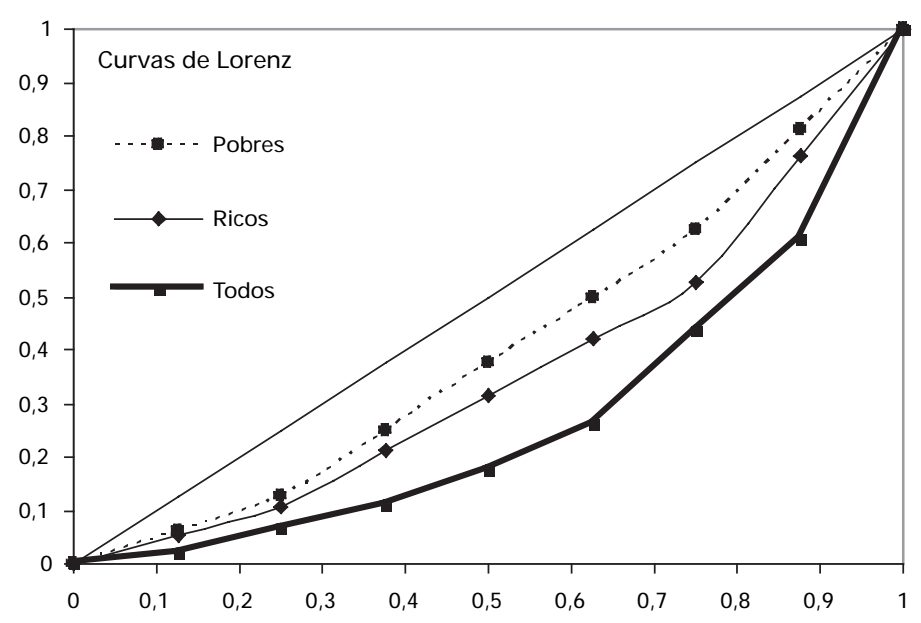

Pode-se verificar que o Índice de Gini para o bairro dos pobres é baixo, de apenas 0.19 , enquanto que, entre os ricos, ficou em 0.28 . Por outro lado, a desigualdade medida quando considerada a distribuição de renda da população total é de 0.46 - ou seja, a curva de Lorenz da cidade como um todo domina em primeira ordem as curvas dos dois bairros.

A partir da ilustração fica claro que a desigualdade de renda que as pessoas des-

\footnotetext{
${ }^{19}$ Para os casos onde só existiam 4 observações (para os bairros), a Curva de Lorenz foi suavizada em 9 pontos.
} 
ta cidade hipotética observam a sua volta depende, em grande medida, de como seus grupos de referência estão definidos - neste exemplo específico, os grupos são delimitados a partir de uma restrição geográfica. $\mathrm{N}$ os dois casos extremos, a desigualdade de renda visualmente percebida pode ser bastante alta, caso os dois bairros mutuamente se reconheçam, ou baixa e diferenciada entre os grupos, caso contrário.

$\mathrm{N}$ a situação onde o grupo de referência não é representativo do ambiente sócio-econômico real (seja ele homogêneo ou, de qualquer outra forma, mal delimitado), a percepção de posicionamento social do indivíduo não será adequada à realidade distributiva da população da qual el e faz parte. $\mathrm{N}$ a ilustração, no caso dos bairros afastados, o cidadão cuja renda é 8 se perceberá à base da escala social, mesmo fazendo parte do bairro mais rico. A percepção de posicionamento social guarda, portanto, uma relação estreita com o grupo de referência utilizado pelo indivíduo.

Voltando à hipótese do artigo, estes elementos permitem interpretar as causas da distribuição de renda desconhecida com base nas noções de delimitação imprecisa de grupos de referência, desvio cognitivo e, ainda, na idéia da heurística da disponibilidade. Em especial, os brasileiros mais ricos, ao se posicionarem nos estratos mais baixos da escala social, provavelmente enquadram-se nesta interpretação indicam desconhecer a relação entreapropriação da renda total edensidadepopulacional a partir do momento em que, fazendo parte de um ambiente social difuso e complexo, não constituem grupos de referência representativos da população brasileira.

\section{Possíveis C onseqüências: Limites ao C onsenso}

A questão da desigualdade de renda vem se tornando cada vez mais central nas agendas de desenvolvimento e de políticas públicas tanto no Brasil como na A mérica Latina. ${ }^{20}$ Embora possa ser dito que as reformas econômicas no decurso dos últimos anos implicaram em uma profunda mudança institucional qualitativa na região (vide estabilização macroeconômica, abertura comercial, liberalização financeira e reestruturação produtiva das firmas e indústrias), as questões sociais evoluem lentamente e a desigualdade de renda permanece alta.

0 recente debate nacional sobre a composição dos gastos públicos federais na área social e seus impactos distributivos é um exemplo claro de que todos os possíveis determinantes da desigualdade de renda no país estão sendo colocados em discussão. ${ }^{21}$ É consensual que a desigualdade de ativos e de oportunidades no Brasil é elevada demais e que o setor público poderia e deveria contribuir mais para o esforço redistributivo. ${ }^{22}$

\footnotetext{
${ }^{20}$ Ver, por exemplo, as agendas de Stallings e Peres (2002), Kuczynski e W illiamson (2003) e Banco M undial (2003 e 2006).

${ }^{21}$ Ver número especial da Econômica, v. 5 n. 1, junho de 2003.

${ }^{22} \mathrm{~A}$ tributação é essencialmente neutra do ponto de vista distributivo (dado o balanço entre um componente indireto regressivo e os componentes de previdência e de renda progressivos) e as transferências monetárias ligeiramente progressivas (SPE/M F, 2003).
} 
$\mathrm{N}$ este artigo parte-se do argumento de que o problema da desigualdade no Brasil é, sobretudo, de economia política - principalmente no que concerne aos seus determinantes institucionais e às soluções contratuais. N este contexto, acredita-se ser chave a criação e a manutenção de um amplo consenso coletivo que sustente politicamente a primazia das soluções de importantes trade-offs de políticas públicas (implícitos ou explícitos) e de estratégias de desenvolvimento em direção à maior igualdade social e ao benefício das camadas historicamente mais desfavorecidas e de menor força política no país.

A criação deste consenso, neste sentido, passa necessariamente pela percepção ou sensibilidade social de todos os atores que fazem parte ativa ou passivamente da legitimação, da sustentação ou das possíveis mudanças que venham a ocorrer no contrato social do país. De acordo com Reis (2000, p. 144), por exemplo:

“... a questão da visão das elites não pode ser subestimada, pois o papel delas na formulação e implementação de políticas sociais é inquestionável. A menos que - por razões interesseiras ou altruístas - elas percebam uma política como necessária ou desejável, esta não terá chance de ser implementada".

Ainda segundo a autora (R eis, 2000, p. 144):

“... reconhecer a importância das elites também não significa negar a importância dos demais atores sociais. 0 comportamento das elites é, em grande parte, reativo às pressões e ações vindas de baixo. Como quer que seja, a maneira como as elites reagem, suas ações e inações são aspectos centrais quando se quer entender a dinâmica das desigualdades e/ou identificar maneiras de combater a pobreza e reduzir as desigualdades".

A hipótese da distribuição de renda desconhecida, neste sentido, enquadra-se como uma interferência na economia política do consenso em prol do combate à desigualdade e a pobreza. A partir do momento em que os brasileiros, mais pobres ou mais ricos, desconhecem como a renda é distribuída no país e o grau de desigualdade existente, o consenso por mais igualdade e menos pobreza perde força.

D estaca-se também neste contexto o próprio erro de posicionamento social subjetivo verificado em todas as camadas da população e, em especial, entre os mais ricos. Seria natural supor que os indivíduos disputam econômica e politicamente os recursos escassos disponíveis em uma população e que, salvo resignação, aqueles localizados nos estratos inferiores da escala social se al egam legítimos de receber uma parcela maior desses recursos. Fica claro, portanto, que existe entre os mais ricos no Brasil uma percepção relativamente forte de que eles não fazem parte do topo da pirâmide, sentimento este que pode ter como origem a elevada desigualdade existente no próprio topo da distribuição de renda. Um problema grave pode surgir, portanto, quando os brasileiros $10 \%$ mais ricos, detentores de aproximadamente $50 \%$ de toda a renda nacional, ainda sim, se considerarem legítimos a rece- 
ber mais recursos na disputa política da repartição, decorrente do simples fato de que não se vêem enquanto os efetivamente mais ricos.

\section{CONSIDERAÇÕES FINAIS}

No Brasil existe o reconhecimento de que as desigualdades são elevadas o que pode ser verificado na mídia, nas relações sociais do cotidiano ou comprovado nas estatísticas oficiais. Q uando aos brasileiros é perguntado "as diferenças de renda são muito grandes em seu país?" ou "dentre estas imagens de sociedade, qual que melhor descreve o seu país?" , eles não hesitam em apontar com severidade o pior dos quadros.

Este artigo apresentou argumentos no sentido de mostrar que o pior dos quadros presente no ideário dos brasileiros parece não se fundamentar no quadro real. N este sentido, apresentaram-se evidências empíricas de que os brasileiros, apesar de indicarem o Brasil como um país qualitativamente desigual, em grande medida, parecem desconhecer como a renda é de fato distribuída no país. A partir deste ponto, abrem-se argumentos que mostram a existência de um quadro de desconhecimento ainda mais amplo, relacionado à questão da magnitude da pobreza e da própria desigualdade de renda. Por fim, pode-se remeter a discussão das possíveis causas e conseqüências da hipótese da distribuição de renda desconhecida à necessidade de conscientização contínua dos brasileiros sobre o grau das desigualdades existentes no país e sobre a posição que efetivamente lhes cabe no contrato social.

\section{REFERÊNCIAS BIBLIOGRÁFICAS}

A kerlof, G.A. e J.L. Yellen (1990). The Fair Wage - Effort H ypothesis and Unemployment. Q uarterly Journal of Economics 105, pp. 255-284.

Banco M undial (2006). World Development Report 2006: Equity and Development. Banco M undial, Washington DC.

. (2003). Inequality in Latin A merica and the Caribbean: Breaking with H istory? Advanced Conference Edition, Banco M undial, Washington DC.

Berrebi, Z.M . e Silber, J. (1985). Income Inequality Indices and D eprivation: a Generalization. Q uarterly Journal of Economics, 100, pp. 807-810.

Boskin, M . and E. Sheshinski (1978). O ptimal Redistributive Taxation When Individual Welfare Depends Upon Relative Income. Q uarterly J ournal of Economics 92, pp. 589-601.

Clark, A. (1993). A ssociative Engines: Connectionism, Concepts and Representational Change. M IT Press, Bradford Books.

Clark, A., O swald, A. (1996). Satisfaction and Comparison of Income. Journal of Public Economics, n. 61, v. 3, pp. 359-381.

Chakravarty, S.R. e Chakraborty, A.B. (1984). O n Indices of R elative Deprivation. Economic Letters, 14 pp. $283-287$.

Denzau, A. e N orth, D. (1994). Shared M ental M odels: Ideologies and Institutionas. Kyklos, v. 47(1), pp. 3-31.

Dosi, G. M arengo, L. e Fagiolo, G. (1996). Learning in Evolutionary Environments. Working Paper 
WP 1996-05. Computable and Experimental Economics Laboratory, Dept. of Economics, University of Trento.

Duclos, J-Y. e Gregoire, P. (2003). A bsolute and R elative Deprivation and the M easurement of Poverty. Cahier de Recherche, WP 02-03.

Durkheim, E. (1933). The Division of Labour in Society. Glencoe IL: Free Press.

Econômica (2003). Gasto Público Social no Brasil. Econômica, v.5, n.1.

Evans, M. D. R. e K elley, J. (2004). Subjective Social Location: Data From 21 N ations. International Journal of Public O pinion R esearch, v.16, n.1, pp. 3-38.

H ey, J.D. e Lambert, P.J. (1980). R elative Deprivation and the Gini Coefficient: Comment. Q uarterly Journal of Economics, 95, pp. 567-573.

H yman, H. (1942). The Psychology of Subjective Status. Psychological Bulletin, 39, pp. 473-474.

H olland, J.H ., H olyoak, K.J., N isbett, R. e Thagard, P. (1986). Induction: Processes of Inference, Learning and Discovery. M IT Press, Cambridge, M A.

IPEA (2005). Radar Social. Instituto de Pesquisa Econômica A plicada, Brasília.

ISSP (2003). ISSP 1999 R eport to the ISSP G eneral Assembly on monitoring work undertaken for the ISSP by ZUM A. Alemanha, mimeo.

Johnson-Laird, P. (1983). M ental M odels. H arvard University Press, Cambridge, M A.

Kahneman, D., Slovic, P. e T versky, H . (1982). Judgment under Uncertainty. Cambridge, England: Cambridge University Press.

Kapteyn, A. e F.G. Van H erwaarden (1980). Interdependent Welfare Functions and O ptimal Income Distribution. Journal of Public Economics 14, pp. 375-397.

Kelley, J. e Evans, M. D. R. (1995). Class and Class Conflict in Six Western N ations. A merican Sociological Review, v.60, pp. 157-178.

Kuczynski, P-P. e Williamson, J. (2003). After the Washington Consensus: R estarting Growth and R eform in Latin A merica. Institute for International Economics, Washington DC.

M argolis, H . (1987). Patterns, Thinking and Cognition. University of Chicago Press, Chicago.

M arx, K. (1983 [1867]). O Capital: Crítica da Economia Política. São Paulo: Abril S. A. Cultural.

M arx, K. e Engels, F. (1988 [1848]). M anifesto do Partido Comunista. Petrópolis: Editora Vozes.

M ayer, R.E. (1992). Thinking, Problem Solving, Cognition. W.H . Freeman, N ova York.

N orth, D. (1996). Economics and Cognitive Science. Washington University, St. Louis, mimeo.

Podder, N . (1996). Relative Deprivation, Envy and Economic Inequality. Kyklos, 49, pp. 353-376.

Reis, E. (2000). Percepções da Elite sobre Pobreza e D esigualdade. R evista Brasileira de Ciências Sociais, v.15, n.42, pp. 143-152.

Rocha, R. (2004). Distribuição de R enda e Percepção da Desigualdade. Dissertação de M estrado em Economia. Instituto de Economia, Universidade Federal do R io de Janeiro. Rio de J aneiro, 2004.

Runciman, W.G. (1966). Relative Deprivation e Social J ustice. H enley: Routledge and Kegan Paul.

Scalon, C. (2004). Imagens da Desigualdade. Belo H orizonte, Ed. UFM G, 2004.

Sen, A. (1976). Poverty: An O rdinal A pproach to M easurement. Econometrica, 44, pp. 219-232.

Sen, A., (1981). Poverty and Famine: An Essay on Entitlement and Deprivation. Clarendon Press, O xford University Press.

SPE/M F (2003). Gasto Social no Governo central 2001 e 2002. Secretaria de Política Econômica, M inistério da Fazenda, Brasília DF.

Stallings, B. e Peres, W. (2002). Crescimento, Emprego e Equidade: o Impacto das R eformas Econômicas na América Latina e Caribe. Campus, Rio de Janeiro.

Stark, O . e Taylor, J.E. (1991). M igration incentives, migration types: the role of relative deprivation. Economic Journal 101, pp. 1163-1178.

Stouffer, S. A., Suchman, E. A., de Vinney, L., Star, S. e W illians J r., R. M . (1949). The A merican Soldier: A djustment during the Army Life. Princeton, N J: Princeton University Press.

Y itzhaki, S. (1979). Relative Deprivation and the Gini Coefficient. Q uarterly J ournal of Economics, 93, pp. 321-324

Woelfel, J. e H aller, A (1971). Significant O thers, the Self-R eflexive Act and the Attitude Formation Process. American Sociological Review, v.36, pp. 74-87. 